\title{
Interannual Variation of the Asian-Pacific Oscillation
}

\author{
Lu Wang and Lin Chen
}

Key Laboratory of Meteorological Disaster, Ministry of Education (KLME) / Joint

International Research Laboratory of Climate and Environmental Change (ILCEC) /

Collaborative Innovation Center on Forecast and Evaluation of Meteorological

Disasters (CIC-FEMD), Nanjing University of Information Science and Technology, Nanjing, China

Corresponding author: Lin Chen, E-mail address: c14v19881005@gmail.com

No. 219, Ningliu Road, Nanjing University of Information Science \& Technology, Nanjing,

Jiangsu 210044, China 
Abstract

\section{Previous studies have identified an Asian-Pacific Oscillation (APO)} teleconnection pattern, which exhibits an out-of-phase relationship in the summer tropospheric temperature with warming over the Eurasia and cooling over the Northern Pacific and the Northern America, and vice versa. But the interannual variation of this teleconnection remains obscure. This study points out that the APO is associated with the second empirical orthogonal function (EOF) mode of the interannual anomalies of boreal summer tropospheric temperature, which accounts for $13.7 \%$ of total variance. Heat budget analysis shows that the seesaw-temperature distributions are resulted from different processes. For the Eurasia region, the warming (cooling) is contributed by the adiabatic heating (cooling) process due to downward (upward) anomalies. For the Northern Pacific region, the temperature variation is mainly contributed by zonal advection associated with interannual zonal wind perturbation acting on the climatological temperature gradient. Composite analysis shows the interannual zonal wind perturbation is related to the sea surface temperature anomalies over the equatorial eastern Pacific. Numerical experiments with an atmospheric general circulation model also demonstrate this relationship.

Key words: Atmospheric teleconnection; Eurasia- Pacific; Boreal summer; Atmospheric temperature 


\section{Introduction}

The teleconnections in the Northern Hemisphere $(\mathrm{NH})$ during boreal summer have received much attention, because they act as a significant source of climate variability and predictability over the NH extratropics (e.g., Ding and Wang 2007; Lee et al. 2014; Ha et al. 2012; Zhang and Zhou 2012; Wu et al. 2016a; Wang et al. 2013). They have been documented to modulate surface air temperature in both the tropics and extratropics (Ding et al 2011, Wu et al. 2016b), rainfall (Nitta and $\mathrm{Hu}$ 1996; Kosaka et al. 2011), tropical cyclone activity (Choi et al. 2010; Kim et al. 2012) and synoptic-scale variabilities ( $\mathrm{Li}$ et al. 2014). Moreover, they have also been invoked in numerous studies of climatic extreme events, such as 2009 cool summer over northern Central Asia, East Asia and centeral North America (Ha et al. 2012), the 1988 drought and the 1993 flood over North America (e.g., Trenberth et al. 1988; Trenberth and Guillemot 1996). Hence, it is conceivable that an improved understanding of the global teleconnections is of great utility and economic value.

Previous studies have detected different teleconnection patterns in $\mathrm{NH}$ during boreal summer. For example, Barnston and Livezey (1987) pointed out three significant teleconnection patterns: North Atlantic Oscillation, a subtropical zonal mode, and a single-centered Asian monsoon mode. A Eurasian teleconnection pattern along the westerly jet stream was also recognized (e.g., Lu et al. 2002). A meridional dipole-like vorticity pattern over the western Pacific and the Philippine Sea features the PacificJapan (PJ) teleconnection pattern (Nitta 1987, Kosaka and Nakamura 2006). By analyzing monthly anomalous geopotential height at $200 \mathrm{hPa}$, Ding and Wang (2005) identified a circumglobal teleconnection (CGT), which is primarily a zonally oriented wave train along the westerly waveguide and is in association with the Indian summer monsoon rainfall anomaly. They later revealed a western North Pacific-North 
America (WPNA) pattern (Ding et al. 2011), which features a wave train emanating from the western Pacific monsoon trough and following a great circle. El NiñoSouthern Oscillation (ENSO) cycle is shown to play a role in the wave structures (Ding et al. 2011).

More recently, based on analysis of seasonal mean [June-August (JJA)] anomalous temperature averaged over $500 \mathrm{hPa}-200 \mathrm{hPa}$, Zhao et al. (2007) identified an Asian-Pacific oscillation (APO) pattern which is characterized by a zonal seesaw of tropospheric temperature in mid-latitudes of the Asian-Pacific region. When the troposphere is warming in the mid-latitudes of the Asian continent, it is cooling in the mid-latitudes of the central and eastern North Pacific as well as in North America and the North Atlantic Ocean, and vice versa. It reflects an out-of-phase relationship between Asia and the North Pacific; the intensity of which have an influence on the tropical cyclone activities over the western North Pacific (WNP) and movement of Mei-yu front (Zhao et al. 2011a). The APO index shows multiple time scale variability, including interannual, decadal and multi-decadal variations (Zhao et al. 2010; Zhao et al. 2012a). The formation of the lower-frequency of APO (e.g., decadal) is suggested to be due to the zonal vertical circulation caused by a difference in the solar radiative heating between the Asian continent and the North Pacific. The Asian land (including the Tibetan Plateau) heating anomalies is the main contributor, while the sea surface temperature (SST) anomalies over the Pacific Ocean do not exert strong influence (Zhao et al. 2012b; Zhao et al. 2011b; Zhou et al. 2010).

Although the previous studies have made some progress in understanding the APO, some questions still remain unsolved. For example, how prominent is the APO pattern in the interannual variability of the extratropical $\mathrm{NH}$ circulation? What factors lead to the zonal seesaw pattern on interannual time scale? Is it the same as in the 
decadal time scale? With these questions in mind, we conduct this study to revisit this phenomenon.

The rest of this paper is organized as follows. The datasets and methods are described in section 2, the dominant modes of interannual variation of tropospheric temperature and its association with APO is examined in section 3, heat budget is conducted for the two main centers related to APO respectively in section 4 to understand the physical mechanism underlying the out-of-phase relationship. Finally, a summary is shown in section 5 .

\section{Data and methods}

This study uses the monthly ERA-40 reanalysis with a horizontal resolution of $2.5 \times 2.5$ (Uppala et al. 2005) and the monthly SST from the HadISST dataset with a resolution of $1 \times 1$ (Rayner et al. 2003) during 1958-2001. In this study, interannual anomalies of summer tropospheric temperature is defined as JJA mean temperature averaged over $500 \mathrm{hPa}-200 \mathrm{hPa}$, which has been subject to removal of climatological annual cycle and linear trend. Note that we didn't artificially remove the zonal average temperature, which was performed in Zhao et al. (2007), to avoid overestimating the zonal asymmetric components. To reveal the loadings of the APO on the interannual variation of extratropical $\mathrm{NH}$ atmosphere, an area-weighted empirical orthogonal function (EOF) analysis is conducted over the temporal correlation matrix of the interannual anomalies of summer tropospheric temperature over the $\mathrm{NH}\left(20^{\circ} \mathrm{N}-55^{\circ} \mathrm{N}, 20^{\circ} \mathrm{E}-40^{\circ} \mathrm{W}\right)$. 
$119 \frac{\partial T}{\partial t}=-\mathbf{V} \cdot \nabla T+\omega\left(\frac{R T}{c_{p} p}-\frac{\partial T}{\partial p}\right)+\frac{Q_{1}}{c_{p}}$

120 where $T$ denotes temperature, $\mathbf{V}$ horizontal velocity vector, $\omega$ vertical pressure

121 velocity, $c_{p}$ denotes the specific heat at constant pressure, $R$ the gas constant, $L$ the

122 latent heat of condensation. The term on the left hand side (lhs) of the equation

123 denotes temperature tendency. The first term on the right hand side (rhs) represents

124 horizontal advection of temperature, the second term adiabatic heating/cooling

125 processes induced by vertical motion and the third term diabatic heating/cooling

126 processes including radiation latent heating, surface heat flux and subgrid-scale

127 processes. $Q_{1}$ is calculated from residual term of daily temperature equation as in 128 Yanai (1973).

3.Major modes of interannual variability of the summer tropospheric temperature anomalies and its association with APO

Figures 1a,c present the first two EOF modes of the JJA-mean temperature anomalies averaged over $500 \mathrm{hPa}-200 \mathrm{hPa}$. They account for $28.7 \%$ and $13.7 \%$ of the total variances, respectively, and can be distinguished from each other and the rest higher modes according to the criteria of North et al. (1982) (see Fig. 2).

The first EOF mode (EOF1) displays zonally symmetric signals over the global mid-latitudes as well as with wave structures embedded, indicating a consistent 
pattern revealed by Ding and Wang (2005), it is found that the structure of this $\mathrm{NH}$ extratropical teleconnection is similar to that of the CGT.

The second EOF mode (EOF2) is characterized by a zonal dipole structure with areas of positive loadings observed over Eurasia and negative loadings over the Pacific and the North America. The out-of-phase relationship shown in EOF2 is similar to the APO pattern revealed by Zhao et al. (2007). Furthermore, the standardized time series of PC2 shows a significantly correlation coefficient $(0.84)$ with the detrended APO index defined in Zhao et al. (2007). This indicates that the EOF2 mode indeed corresponds to the APO teleconnection. Our results suggest that the APO on interannual time scale is associated with the second dominant mode of the interannual temperature anomalies over $\mathrm{NH}$ and accounts for $13.7 \%$ of the total variances. Note that Zhao et al. (2010) have suggested that the APO is associated with the first EOF mode of upper-tropospheric temperature anomalies and account for $27 \%$ of the total variances. The difference is because they have artificially deducted the zonal mean from the temperature field before applying EOF analysis and the zonal dipole mode is overestimated.

\section{Mechanisms for the zonal asymmetric structure of temperature anomalies}

To further understand the formation of the EOF2 pattern or the APO, we separately address the causes for the temperature anomalies over the Eurasia and over the North Pacific in the following sections. Two boxes covering the temperature anomaly centers are selected to be focused on (i.e., $\left(30^{\circ} \mathrm{N}-50^{\circ} \mathrm{N}, 60^{\circ} \mathrm{E}-120^{\circ} \mathrm{E}\right)$ and $\left(20^{\circ} \mathrm{N}-40^{\circ} \mathrm{N}, 180^{\circ}-120^{\circ} \mathrm{W}\right)$, see rectangles in Fig. 1c). We chose these two boxes because they are very close to the regions for the original definition of the APO index 
163 (Zhao et al. 2007). Moreover, the positive-index years and the negative-index years 164 are selected according to the standardized time series of PC2 with its values beyond 1

$165(-1)$ (see Table 1). Then, composite results are obtained by the difference between the 166 average of the positive-index years and the average of the negative-index years 167 (positive-index years minus negative-index years), and reflect the case with warming over the Eurasia and cooling over the North Pacific and the North America.

\subsection{Causes of warming over the Eurasia}

Figure 3 displays the time evolution of composited temperature anomalies averaged over the Eurasia box and its time tendency. As expected, apparent positive anomalies appear during JJA. The maximum warming tendency is found in May. We therefore conduct heat budget analysis of the composited temperature tendency in May to reveal the dominant processes that lead to the warming tendency.

Relative contributions of each budget terms are shown in Fig. 4. It is found that the positive temperature tendency is contributed by the adiabatic process while the horizontal advection and diabatic processes all play an opposite role. Fig. 5a presents the composite of pressure velocity profile averaged over the Eurasia box. Most of 179 troposphere exhibits downdraft motion. As downdraft motion would warm the atmosphere by adiabatic process, the positive temperature tendency over the Eurasia in May is due to downward anomalies.

\subsection{Causes of cooling over the North Pacific}

Figure 6 displays the time evolution of composited temperature anomalies averaged over the North Pacific box and its time tendency. As expected, apparent negative anomalies appear during JJA. The maximum cooling tendency is found in 
June. We therefore conduct heat budget analysis of the temperature tendency in June to reveal the dominant processes that lead to the cooling tendency.

Relative contributions of each budget terms are shown in Fig. 7a. The negative tendency is contributed by the horizontal advection and diabatic processes while the adiabatic process tends to result in positive tendency. As shown in Fig. 5b, there are downward anomalies in the upper troposphere and upward anomalies in the lower troposphere. The downdraft motion in the upper troposphere could induce adiabatic warming and diabatic cooling at the same time, as latent heat release related to convection could be suppressed by downdraft motion. As is inferred from Fig. 7a, the total effect of the downdraft motion over the North Pacific region is to increase the positive temperature tendency. Therefore, the horizontal advection term is considered to dominate the cooling process. Furthermore, we decompose the horizontal advection term as follows

$$
(-\mathbf{V} \cdot \nabla T)^{\prime}=-\bar{u} \frac{\partial T^{\prime}}{\partial x}-u^{\prime} \frac{\partial \bar{T}}{\partial x}-u^{\prime} \frac{\partial T^{\prime}}{\partial x}-\bar{v} \frac{\partial T^{\prime}}{\partial y}-v^{\prime} \frac{\partial \bar{T}}{\partial y}-v^{\prime} \frac{\partial T^{\prime}}{\partial y},
$$

where a bar denotes climatological average and a prime denotes interannual perturbation which is obtained by removal of annual cycle and linear trend. As shown in Fig. $7 \mathrm{~b}$, the dominant contributor for the composited cold horizontal advection in June is the interannual zonal wind perturbation acting on the climatological temperature gradient.

To understand the physical mechanism for the cold advection, we present the composite of 500-200 hPa averaged horizontal wind perturbations and multi-year mean temperature in June in Fig. 8. It is found that over the North Pacific box are 
strong easterly anomalies. As a strong temperature trough exists in the eastern part of the box, the easterly wind could induce cold horizontal advection.

Then, what causes the strong easterly anomalies over the North Pacific box? Note that the easterly anomalies are associated with a cyclonic gyre centered at $\left(20^{\circ} \mathrm{N}\right.$, $180^{\circ} \mathrm{E}$ ), we therefore intend to understand the formation of the cyclonic gyre. Fig. 9 shows the composited SST anomaly and $850-\mathrm{hPa}$ wind anomaly in June. The SST anomaly shows a La Niña -like pattern with cold SST anomaly over the equatorial eastern Pacific. Strong easterly anomalies are observed over the equator; and a pair of anticyclonic gyres (with marks of "A") is observed flanking the equator to the west of the coldest SST anomaly pool. Meanwhile, in the upper troposphere apparent westerly anomalies are observed over the equator as well as a pair of cyclonic gyres (with marks of "C", see Fig. 8). Based on the observed features, it is possible that the upperlevel cyclonic gyres and lower-level anticyclonic gyres are due to Gill response to the underlying cold SST anomaly (Gill 1980). Note that significant positive SST anomaly is also observed in the mid-latitude North Pacific region and one may suspect that it could also impact the overlying atmospheric circulations. However, it has been demonstrated that the formation of such a warming pattern is mainly due to atmospheric forcing associated with the surface anticyclonic circulation while SST's impact on atmosphere is weak (Wang et al. 2012; Wang et al. 2013).

To prove or disapprove our hypothesis that the upper-tropospheric cyclonic gyres are due to La Niña-like SST anomaly forcing, we use atmospheric general circulation model (AGCM) ECHAM (v4.6) (Roeckner et al. 1996) at T42 horizontal resolution to design numerical experiments. In addition to the control run (CTRL), which was forced by the monthly climatological SST field, -1 K SST cooling was added on the SST forcing field of June over the box located at the equatorial eastern Pacific ocean 
$\left(15^{\circ} \mathrm{S} \sim 10^{\circ} \mathrm{N}, 160^{\circ} \mathrm{E} \sim 80^{\circ} \mathrm{W}\right.$ ) (see rectangles in Fig. 9) in the sensitivity experiment. In both experiments, model was integrated for 30 years and results from the last 20 years were analyzed. The difference of wind fields in June between the average from the CTRL run and that from the sensitivity run represents response to the cold SST anomaly over the eastern Pacific. Fig. 10 shows the upper-level wind response obtained from the experiments. A pair of cyclonic gyres (marked with "C") is found flanking the equator, and in the key box over the North Pacific, there is strong easterly anomaly. The above numerical experiment results suggest that the cooling of tropospheric temperature over the North Pacific region is related to the cold SST anomaly over the equatorial eastern Pacific.

\section{Conclusion}

In this study, we examined the dominant modes of the interannual variation of summer tropospheric temperature over the mid-latitude Northern hemisphere $(\mathrm{NH})$ with the ERA-40 reanalysis. The first EOF mode is similar to the circumglobal teleconnection (CGT) pattern while the second EOF mode is associated with the Asian-Pacific Oscillation (APO). The APO reflects an out-of-phase relationship in the summer tropospheric temperature with warming (cooling) over the Eurasia and cooling (warming) over the Northern Pacific and the Northern America. It accounts for $13.7 \%$ of the total variances of the interannual variations of mid-latitude $\mathrm{NH}$ temperature.

Heat budget analysis shows that the seesaw-temperature distributions are resulted from different processes. For the Eurasia region, the warming (cooling) is contributed by the adiabatic heating (cooling) process induced by downward (upward) anomalies. 
257 For the Northern Pacific region, the temperature variation is mainly due to zonal 258 advection associated with interannual zonal wind anomalies acting on the 259 climatological temperature gradient. For the cooling over the Northern Pacific, the 260 cold advection is due to strong easterly anomaly in the box, which is associated with a 261 pair of cyclonic gyres flanking the equator in upper troposphere. Further analysis 262 shows that the upper-level cyclonic gyres are due to the Gill response to La Niña-like 263 SST anomalies over the equatorial eastern Pacific. The vice is versa for the warming 264 in the Northern Pacific region. Numerical experiments with an AGCM also prove this 265 relationship.

268 Acknowledgements. This work was supported by China National 973 project 269 2015CB453200, NSFC grant 41475084/41375058, NRL grant N00173-16-1-G906, 270 ONR grant N00014-16-12260, Jiangsu Natural Science Foundation Key project 271 BK20150062, and Jiangsu Shuang-Chuang Team R2014SCT001. This is SOEST 272 contribution number $\mathrm{xxxx}$, IPRC contribution number $\mathrm{xxxx}$, and ESMC contribution 273 number xxx. 
Barnston, A. G., and R. E. Livezey, 1987: Classification, seasonality and persistence of lowfrequency atmospheric circulation pat-terns. Mon. Wea. Rev., 115, 1083-1126.

Choi, K. S., C. C. Wu, and E. J. Cha, 2010: Changes of tropical cyclone activity by PacificJapan teleconnection pattern in the western North Pacific. J. Geophys. Res., 115, D19114, doi:10.1029/2010JD013866.

Ding, Q. and B. Wang, 2005: Circumglobal Teleconnection in the Northern Hemisphere Summer. Journal of Climate, 18, 3483-3505.

Ding and Wang, 2007: Intraseasonal teleconnection between the summer Eurasian wave train and the Indian monsoon. J. Climate, 20, 3751-3767.

284

285

286

Ding, Q., B. Wang, J. M. Wallace and G. Branstator, 2011: Tropical-Extratropical Teleconnections in Boreal Summer: Observed Interannual Variability. Journal of climate, 24, 1878-1896.

Gill, A. E., 1980: Some simple solutions for heat-induced tropical circulation. Quarterly Journal of the Royal Meteorological Society, 106, 447-462.

Ha, K.-J., J.-E. Chu, J.-Y. Lee, B. Wang, N. H. Saji and M. Watanabe, 2012: What caused the cool summer over northern Central Asia, East Asia and central North America during 2009? Environmental Research Letters, 7, 044015.

Kim, J.-S., R. C. Y. Li, and W. Zhou, 2012: Effects of the Pacific-Japan teleconnection pattern on tropical cyclone activity and extreme precipitation events over the Korean Peninsula. J. Geophys. Res., 117, D18109, doi:10.1029/2012JD017677.

Kosaka, Y. and H. Nakamura, 2006: Structure and dynamics of the summertime PacificJapan teleconnection pattern. Quarterly Journal of the Royal Meteorological Society, 132, 2009-2030.

Kosaka, Y., S.-P. Xie and H. Nakamura, 2011: Dynamics of Interannual Variability in Summer Precipitation over East Asia. Journal of climate, 24, 5435-5453.

Lee, J.-Y., B. Wang, K.-H. Seo, J.-S. Kug, Y.-S. Choi, Y. Kosaka and K.-J. Ha, 2014: Future Change of Northern Hemisphere Summer Tropical-Extratropical Teleconnection in CMIP5 Models. Journal of climate, 27, 3643-3664.

Li, R. C. Y., W. Zhou and T. Li, 2014: Influences of the Pacific-Japan Teleconnection Pattern on Synoptic-Scale Variability in the Western North Pacific. Journal of climate, 27, 140-154.

Lu, R.-Y., J.-H. Oh, and B.-J. Kim, 2002: A teleconnection pattern in upper-level meridional wind over the North African and Eurasian continent in summer. Tellus, 54A, 44-55.

Nitta, T., 1987: Convective activities in the tropical western Pacific and their impact on the northern hemisphere summer circulation. J. Meteor. Soc. Japan, 65, 373-390.

Nitta, T. and Z.-Z. Hu, 1996: Summer climate variability in China and its association with $500 \mathrm{hPa}$ Height and Tropical Convection. J Meteorol Soc Jpn, 74, 425-445. 
North, G. R., T. L. Bell, R. F. Cahalan and F. J. Moeng, 1982: Sampling Errors in the Estimation of Empirical Orthogonal Functions. Monthly Weather Review, 110, 699706.

Rayner, N., D. Parker, E. Horton, C. Folland, L. Alexander, D. Rowell, E. Kent and A. Kaplan, 2003: Global analyses of sea surface temperature, sea ice, and night marine air temperature since the late nineteenth century. Journal of Geophysical Research, 108, 4407.

Roeckner, E., Coauthors, 1996: The atmospheric general circulation model ECHAM-4: Model description and simulation of present-day climate. Max-Planck-Institut für Meteorologie Rep, 218, 90.

Trenberth, K. E., G. W. Branstator, and P. A. Arkin, 1988: Origins of the 1988 North American drought. Science, 242, 1640-1645.

Trenberth, K. E. and C. J. Guillemot, 1996: Physical processes involved in the 1988 drought and 1993 floods in North America. J. Climate, 9, 1288-1298.

Uppala, S. M., et al., 2005: The ERA-40 re-analysis. Quarterly Journal of the Royal Meteorological Society, 131, 2961-3012.

Wang, L., T. Li and T. Zhou, 2012: Intraseasonal SST Variability and Air-Sea Interaction over the Kuroshio Extension Region during Boreal Summer*. Journal of Climate, 25, 1619-1634.

Wang, L., T. Li, T. Zhou and X. Rong, 2013: Origin of the Intraseasonal Variability over the North Pacific in Boreal Summer*. Journal of Climate, 26, 1211-1229.

Wang, L., T. Li and T. Zhou, 2015: Effect of High-frequency Wind on Intraseasonal SST Variabilities over the Mid-latitude North Pacific Region during Boreal Summer. Climate Dynamics, 2607-2617. DOI:10.1007/s00382-015-2496-2

Wu, B., T. Zhou and T. Li, 2016a: Impacts of the Pacific-Japan and Circumglobal Teleconnection Patterns on the Interdecadal Variability of the East Asian Summer Monsoon. Journal of climate, 29, 3253-3271.

Wu, B., J. Lin and T. Zhou, 2016b: Interdecadal circumglobal teleconnection pattern during boreal summer. Atmospheric Science Letters, DOI: 10.1002/asl.677

Yanai, M., S. Esbensen and J.-H. Chu, 1973: Determination of Bulk Properties of Tropical Cloud Clusters from Large-Scale Heat and Moisture Budgets. Journal of the Atmospheric Sciences, 30, 611-627.

Zhang, L. and T. Zhou, 2012: The Interannual Variability of Summer Upper-Tropospheric Temperature over East Asia. Journal of climate, 25, 6539-6553.

Zhao, P., Y. Zhu and R. Zhang, 2007: An Asian-Pacific teleconnection in summer tropospheric temperature and associated Asian climate variability. Climate dynamics, 29, 293-303.

Zhao, P., Z. Cao and J. Chen, 2010: A summer teleconnection pattern over the extratropical Northern Hemisphere and associated mechanisms. Climate dynamics, 35, 523-534.

Zhao, P., W. Dai and Z. Xiao, 2011a: The Asian-Pacific Oscillation and its Impact on Climate. Advances in Meteorological Science and Technology, 1(2), 6-10. (in Chinese) 
Zhao, P., S. Yang, M. Jian and J. Chen, 2011b: Relative Controls of Asian-Pacific Summer Climate by Asian Land and Tropical-North Pacific Sea Surface Temperature. Journal of climate, 24, 4165-4188.

Zhao, P., B. Wang and X. Zhou, 2012a: Boreal summer continental monsoon rainfall and hydroclimate anomalies associated with the Asian-Pacific Oscillation. Climate dynamics, 39, 1197-1207.

Zhao, P., S. Yang, R. Wu, Z. Wen, J. Chen and H. Wang, 2012b: Asian Origin of Interannual Variations of Summer Climate over the Extratropical North Atlantic Ocean. Journal of climate, 25, 6594-6609.

Zhou, B., P. Zhao and X. Cui, 2010: Linkage between the Asian-Pacific Oscillation and the sea surface temperature in the North Pacific. Chinese Science Bulletin, 55, 1193-1198. 
366 Table 1 Selected years for composite, which is based on the standardized time series

367 of PC2. The positive- (negative-) index years denotes those years with values beyond $3681(-1)$.

\section{Figure captions}

372 Fig. 1 The first two leading modes $(\times 0.01)$ and corresponding normalized principal components of EOF analysis applied to the summer (June to August, JJA) mean temperature anomalies averaged over 500 - 200 hPa: (a) EOF1, (b) PC1, (c) EOF2, (d) PC2. The percent variance is marked on top right of panel (a) and (c). Rectangles in (c) denote East Asian region $\left(30^{\circ} \mathrm{N}-50^{\circ} \mathrm{N}, 60^{\circ} \mathrm{E}-120^{\circ} \mathrm{E}\right)$ and the Northern Pacific region $\left(20^{\circ} \mathrm{N}-40^{\circ} \mathrm{N}, 180^{\circ}-120^{\circ} \mathrm{W}\right)$, which are focused on in this study.

378

Fig. 2 The total variance (\%) explained by each of the first five EOF modes. Error bars are determined by the formula of North et al. (1982).

Fig. 3 Time evolution of composited monthly temperature anomalies (red, K) averaged over $500-200 \mathrm{hPa}$ for the East Asian region $\left(30^{\circ} \mathrm{N}-50^{\circ} \mathrm{N}, 60^{\circ} \mathrm{E}-120^{\circ} \mathrm{E}\right)$ and its tendency (blue, $\mathrm{K}$ month ${ }^{-1}$ ).

Fig. 4 Composite of 500-200 hPa averaged temperature anomalies budget terms (K month $\left.{ }^{-1}\right)$ for the East Asian region $\left(30^{\circ} \mathrm{N}-50^{\circ} \mathrm{N}, 60^{\circ} \mathrm{E}-120^{\circ} \mathrm{E}\right)$ in May. From left to right, observed temperature tendency, horizontal temperature advection, adiabatic term and diabatic term.

Fig. 5 (a) Composite profiles of pressure velocity anomalies $\left(\mathrm{Pa} \mathrm{s}^{-1}\right)$ averaged over the East Asian region $\left(30^{\circ} \mathrm{N}-50^{\circ} \mathrm{N}, 60^{\circ} \mathrm{E}-120^{\circ} \mathrm{E}\right)$ in May. (b) Same as in (a), except for over the Northern Pacific region $\left(20^{\circ} \mathrm{N}-40^{\circ} \mathrm{N}, 180^{\circ}-120^{\circ} \mathrm{W}\right)$ in June.

Fig. 6 Same as in Fig. 3, except for the Northern Pacific region $\left(20^{\circ} \mathrm{N}-40^{\circ} \mathrm{N}, 180^{\circ}-\right.$ $\left.120^{\circ} \mathrm{W}\right)$. 
392 Fig. 7 (a) Composite of 500-200 hPa averaged temperature anomalies budget terms

$393\left(\mathrm{~K} \mathrm{month}^{-1}\right)$ for the Northern Pacific region $\left(20^{\circ} \mathrm{N}-40^{\circ} \mathrm{N}, 180^{\circ}-120^{\circ} \mathrm{W}\right)$ in June. From 394 left to right, observed temperature tendency, horizontal temperature advection, 395 adiabatic term and diabatic term. (b) Decomposition of horizontal advection term in 396 (a).

397 Fig. 8 Composite of interannual wind perturbation (vectors, $\mathrm{m} \mathrm{s}^{-1}$ ) and climatological 398 temperature (shaded, K) in June; both are vertical averaged within 500 -200 hPa. 399 Markers "C" denote cyclonic gyres. The rectangle marks the Northern Pacific region $400\left(20^{\circ} \mathrm{N}-40^{\circ} \mathrm{N}, 180^{\circ}-120^{\circ} \mathrm{W}\right)$.

401 Fig. 9 Composite of interannual wind perturbation at $850 \mathrm{hPa}$ (vectors, $\mathrm{m} \mathrm{s}^{-1}$ ) and sea 402 surface temperature (SST) anomaly (shaded, K) in June. Markers "A" denote 403 anticyclonic gyres. The rectangle marks the equatorial eastern Pacific region $\left(15^{\circ} \mathrm{S}\right.$ $\left.40410^{\circ} \mathrm{N}, 160^{\circ} \mathrm{E}-80^{\circ} \mathrm{W}\right)$, where cold SST anomaly $(-1 \mathrm{~K})$ is prescribed in the sensitivity 405 experiment.

406 Fig. 10 250-hPa wind response to the cold SST anomaly prescribed over the 407 equatorial eastern Pacific region. Markers "C" denote cyclonic gyres. The rectangle 408 marks the Northern Pacific region $\left(20^{\circ} \mathrm{N}-40^{\circ} \mathrm{N}, 180^{\circ}-120^{\circ} \mathrm{W}\right)$. 
413 Table 1 Selected years for composite, which is based on the standardized time series

414 of PC2. The positive- (negative-) index years denotes those years with values beyond $4151(-1)$.

416

\section{Composited years}

Positive index years $1961,1967,1971,1978,1984,1994,2000,2001$

Negative index years $1958,1969,1981,1983,1987,1992,1993,1995$

417

418

419

420 
(a) EOF 1

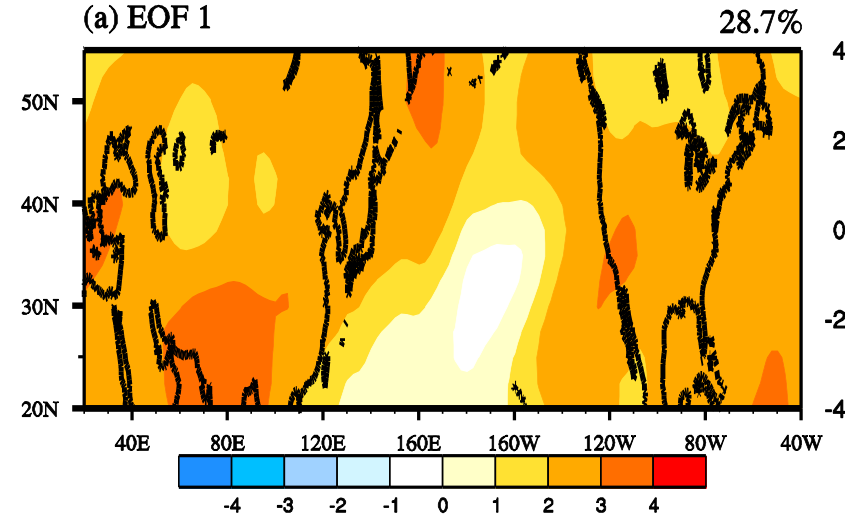

(c) EOF 2

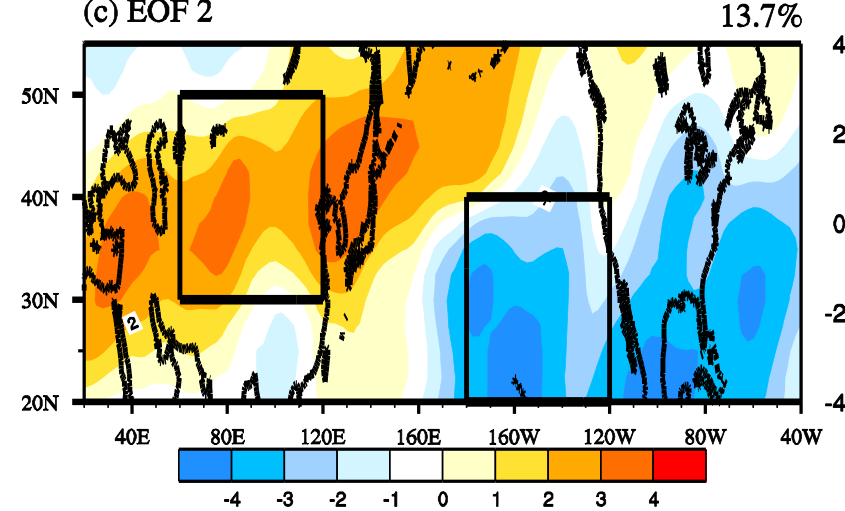

(b) PC1

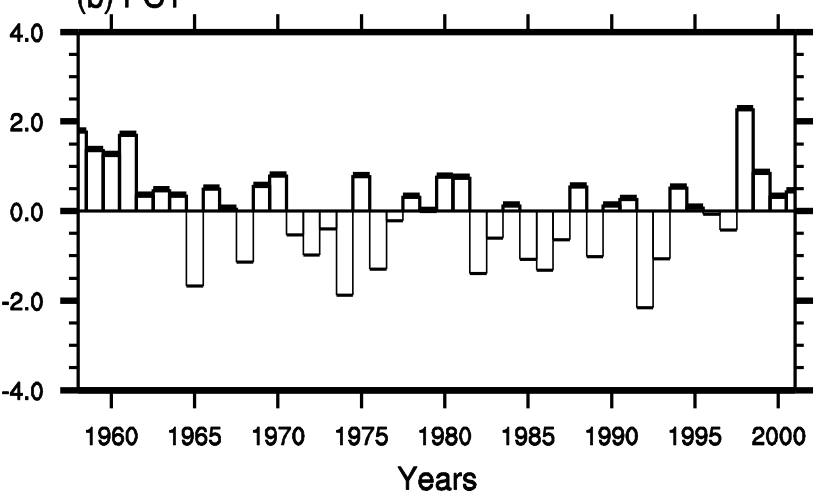

422

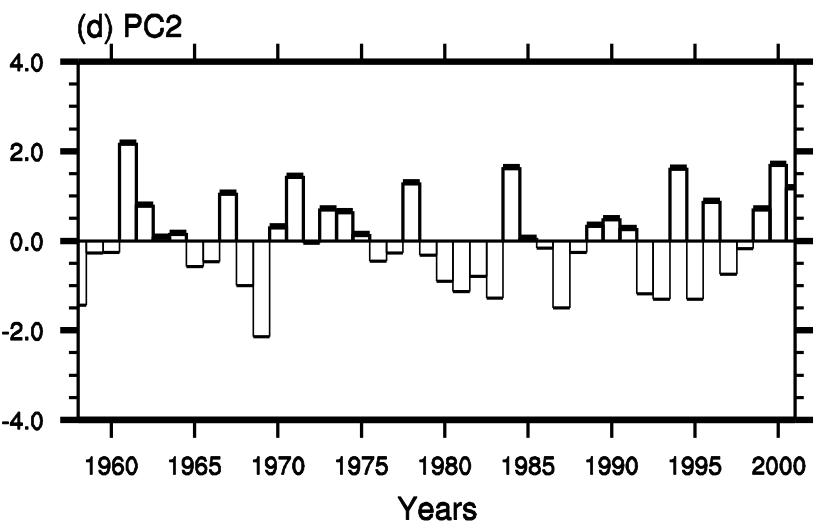

423 Fig. 1 The first two leading modes $(\times 0.01)$ and corresponding normalized principal

424 components of EOF analysis applied to the summer (June to August, JJA) mean

425 temperature anomalies averaged over 500 - 200 hPa: (a) EOF1, (b) PC1, (c) EOF2, (d)

426 PC2. The percent variance is marked on top right of panel (a) and (c). Rectangles in (c)

427 denote East Asian region $\left(30^{\circ} \mathrm{N}-50^{\circ} \mathrm{N}, 60^{\circ} \mathrm{E}-120^{\circ} \mathrm{E}\right)$ and the Northern Pacific region

$428\left(20^{\circ} \mathrm{N}-40^{\circ} \mathrm{N}, 180^{\circ}-120^{\circ} \mathrm{W}\right)$, which are focused on in this study. 


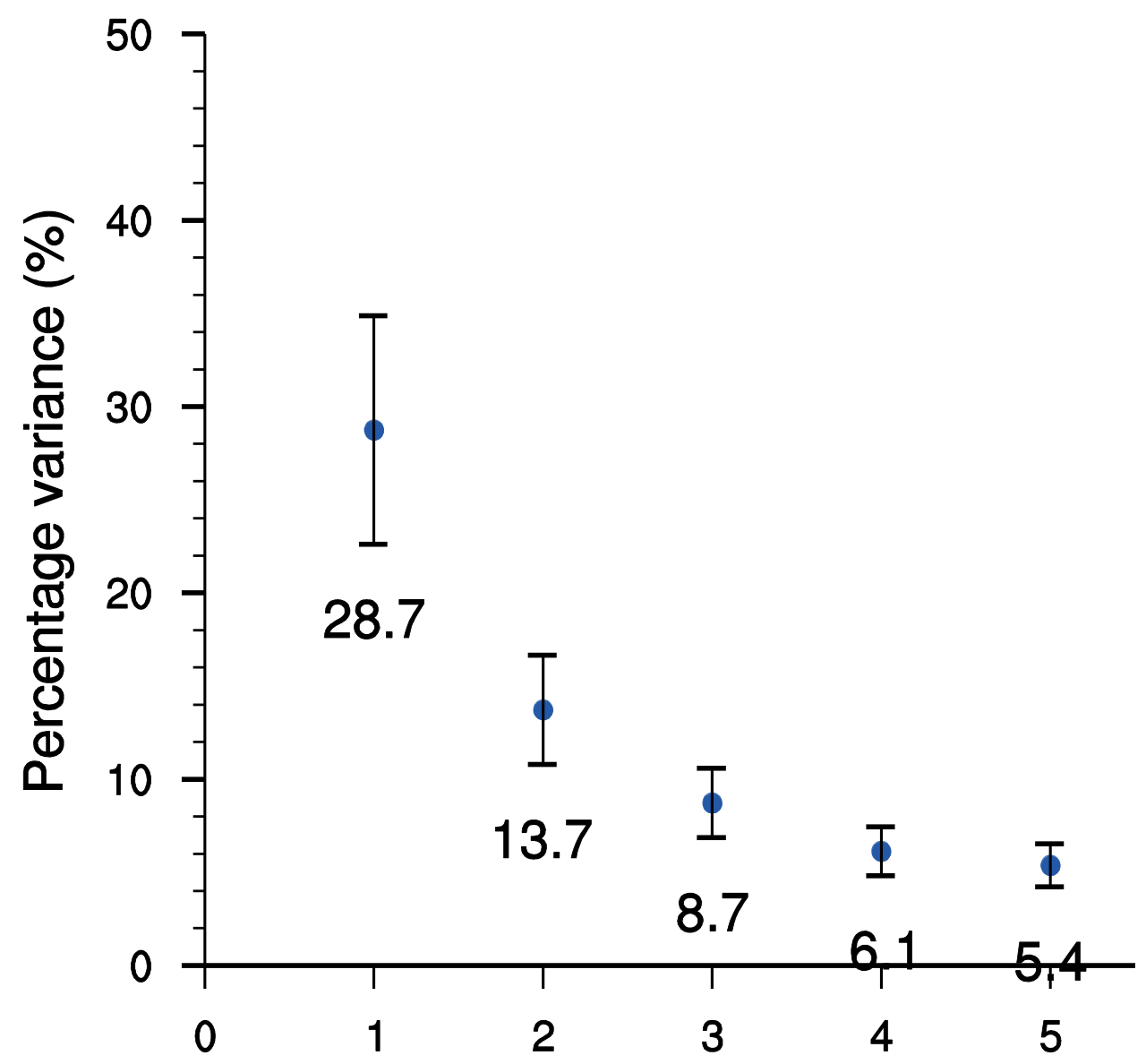

429

430

431 Fig. 2 The total variance (\%) explained by each of the first five EOF modes. Error 432 bars are determined by the formula of North et al. (1982). 


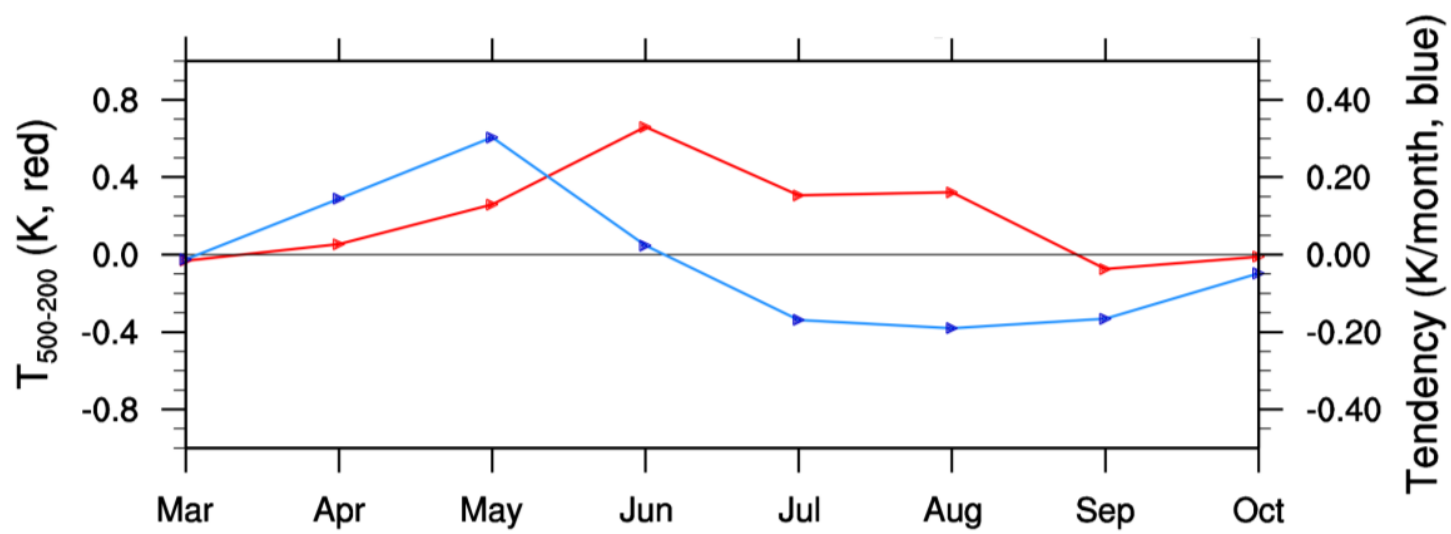

436

437 Fig. 3 Time evolution of composited monthly temperature anomalies (red, K)

438 averaged over $500-200 \mathrm{hPa}$ for the East Asian region $\left(30^{\circ} \mathrm{N}-50^{\circ} \mathrm{N}, 60^{\circ} \mathrm{E}-120^{\circ} \mathrm{E}\right)$ and 439 its tendency (blue, $\mathrm{K} \mathrm{month}^{-1}$ ).

440 


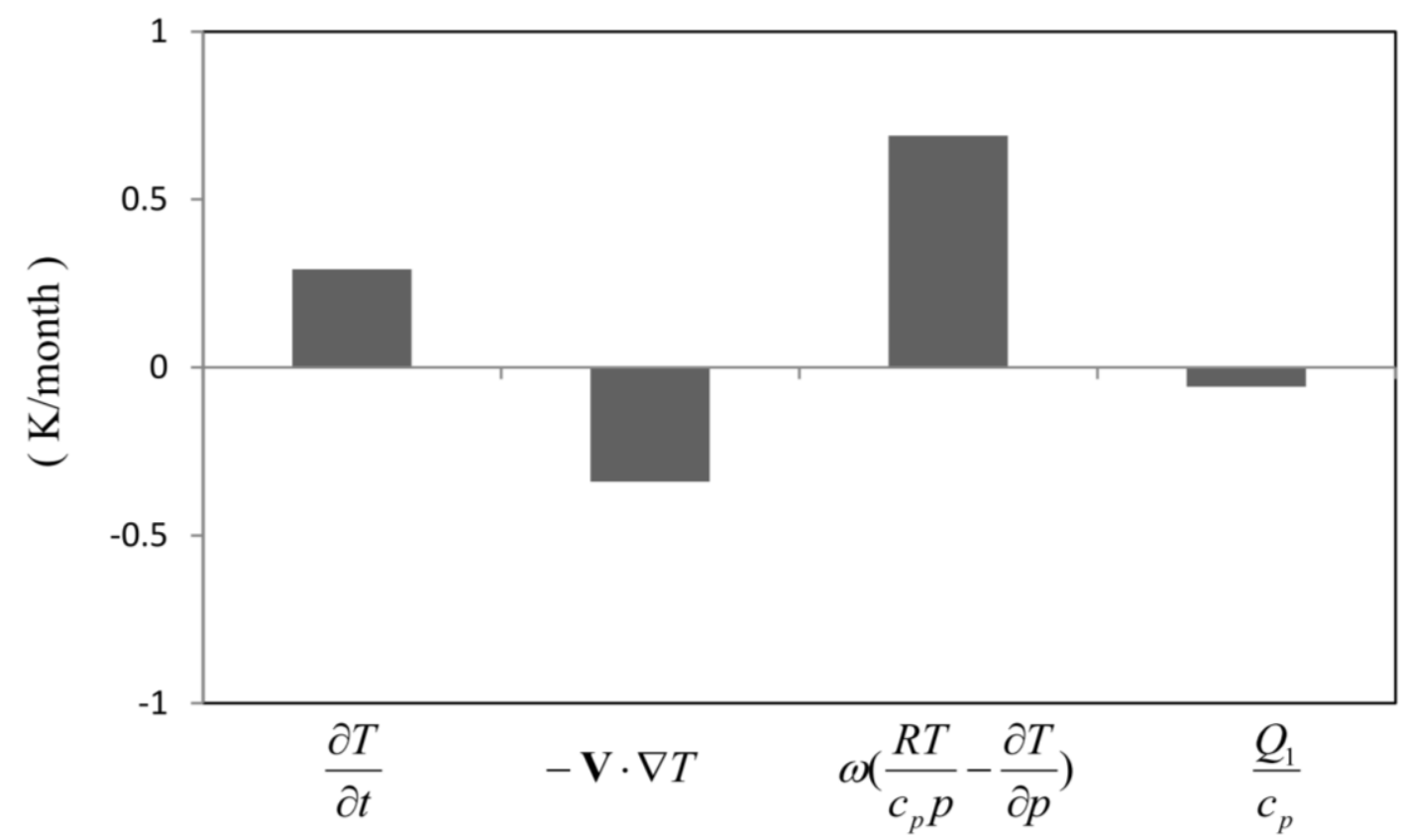

442

443 Fig. 4 Composite of 500-200 hPa averaged temperature anomalies budget terms (K

444 month $\left.{ }^{-1}\right)$ for the East Asian region $\left(30^{\circ} \mathrm{N}-50^{\circ} \mathrm{N}, 60^{\circ} \mathrm{E}-120^{\circ} \mathrm{E}\right)$ in May. From left to 445 right, observed temperature tendency, horizontal temperature advection, adiabatic 446 term and diabatic term.

447 

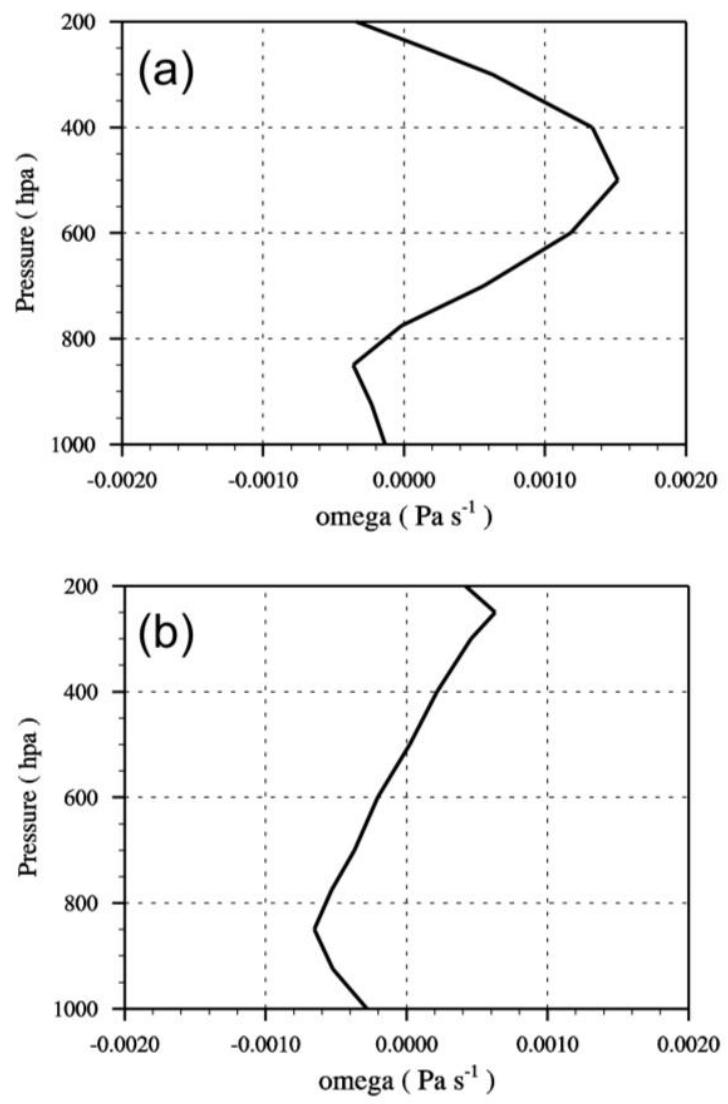

450 Fig. 5 (a) Composite profiles of pressure velocity anomalies $\left(\mathrm{Pa} \mathrm{s}^{-1}\right)$ averaged over the

451 East Asian region $\left(30^{\circ} \mathrm{N}-50^{\circ} \mathrm{N}, 60^{\circ} \mathrm{E}-120^{\circ} \mathrm{E}\right)$ in May. (b) Same as in (a), except for 452 over the Northern Pacific region $\left(20^{\circ} \mathrm{N}-40^{\circ} \mathrm{N}, 180^{\circ}-120^{\circ} \mathrm{W}\right)$ in June. 


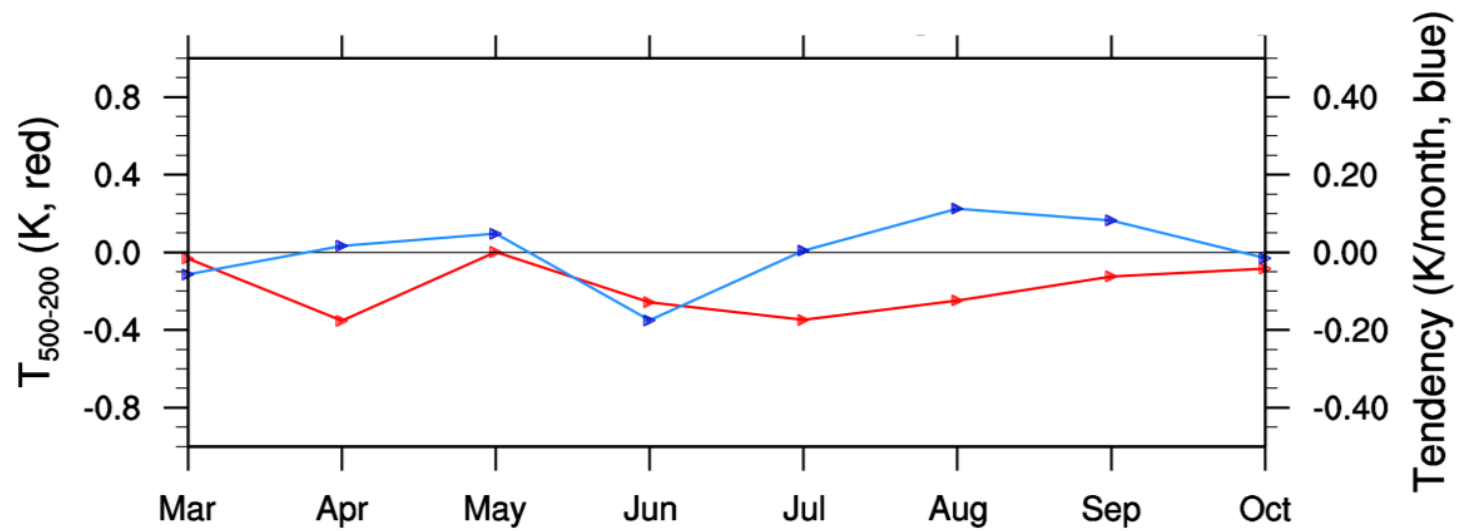

457 Fig. 6 Same as in Fig. 3, except for the Northern Pacific region $\left(20^{\circ} \mathrm{N}-40^{\circ} \mathrm{N}, 180^{\circ}-\right.$ $\left.458120^{\circ} \mathrm{W}\right)$.

459 


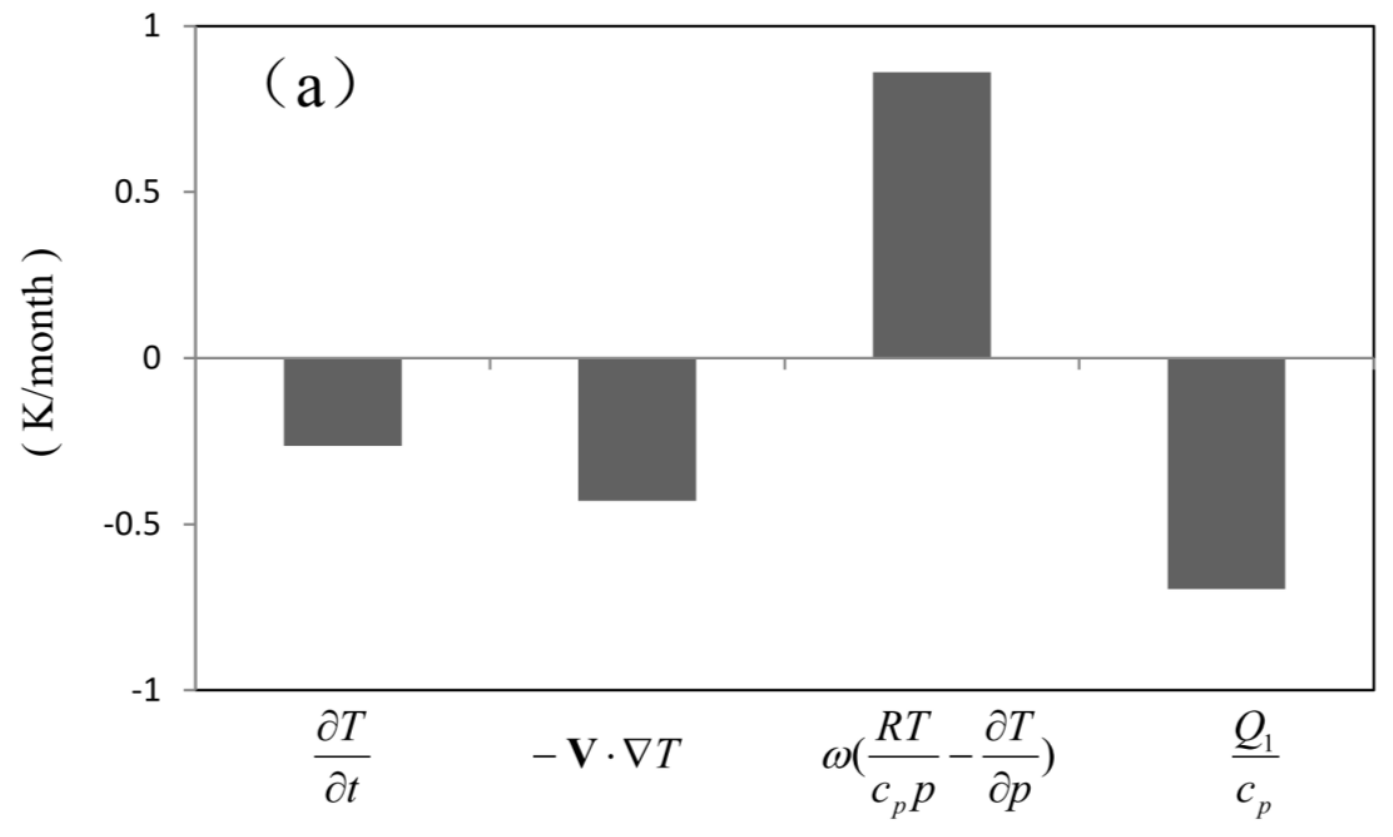

460

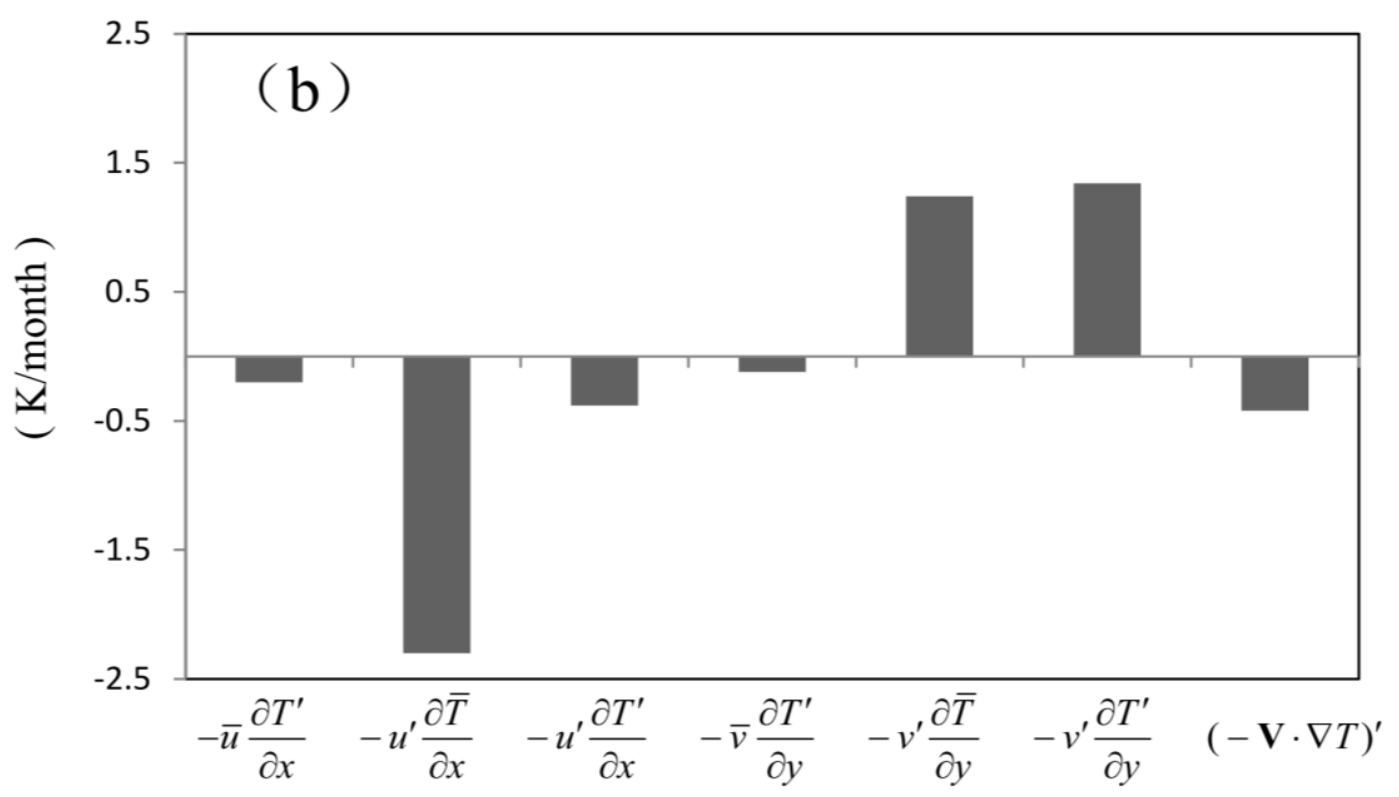

461

462 Fig. 7 (a) Composite of 500-200 hPa averaged temperature anomalies budget terms

$463\left(\mathrm{~K} \mathrm{month}^{-1}\right)$ for the Northern Pacific region $\left(20^{\circ} \mathrm{N}-40^{\circ} \mathrm{N}, 180^{\circ}-120^{\circ} \mathrm{W}\right)$ in June. From 464 left to right, observed temperature tendency, horizontal temperature advection, 465 adiabatic term and diabatic term. (b) Decomposition of horizontal advection term in 466 (a). 

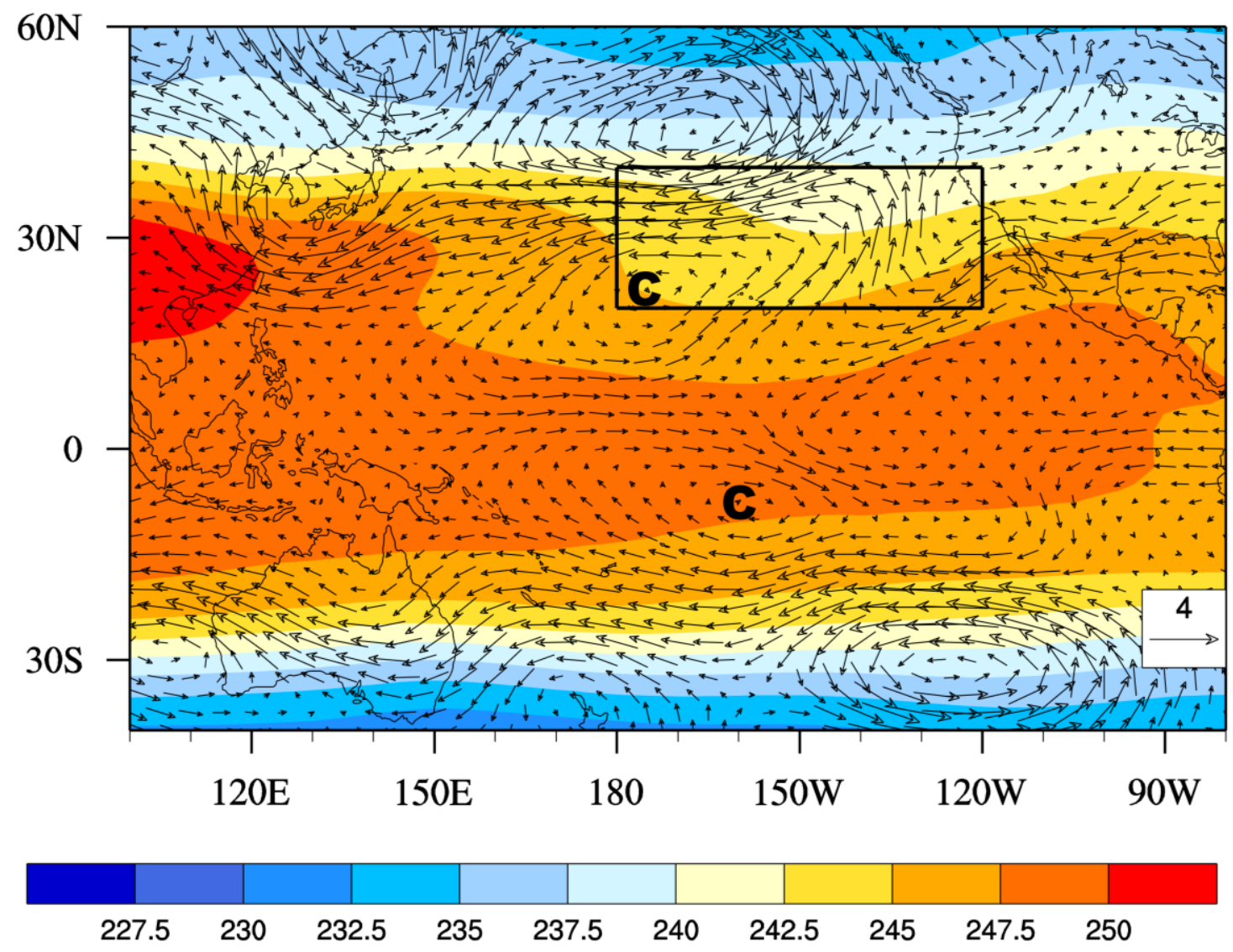

469 Fig. 8 Composite of interannual wind perturbation (vectors, $\mathrm{m} \mathrm{s}^{-1}$ ) and climatological

470 temperature (shaded, K) in June; both are vertical averaged within $500-200 \mathrm{hPa}$.

471 Markers "C" denote cyclonic gyres. The rectangle marks the Northern Pacific region

$472\left(20^{\circ} \mathrm{N}-40^{\circ} \mathrm{N}, 180^{\circ}-120^{\circ} \mathrm{W}\right)$. 


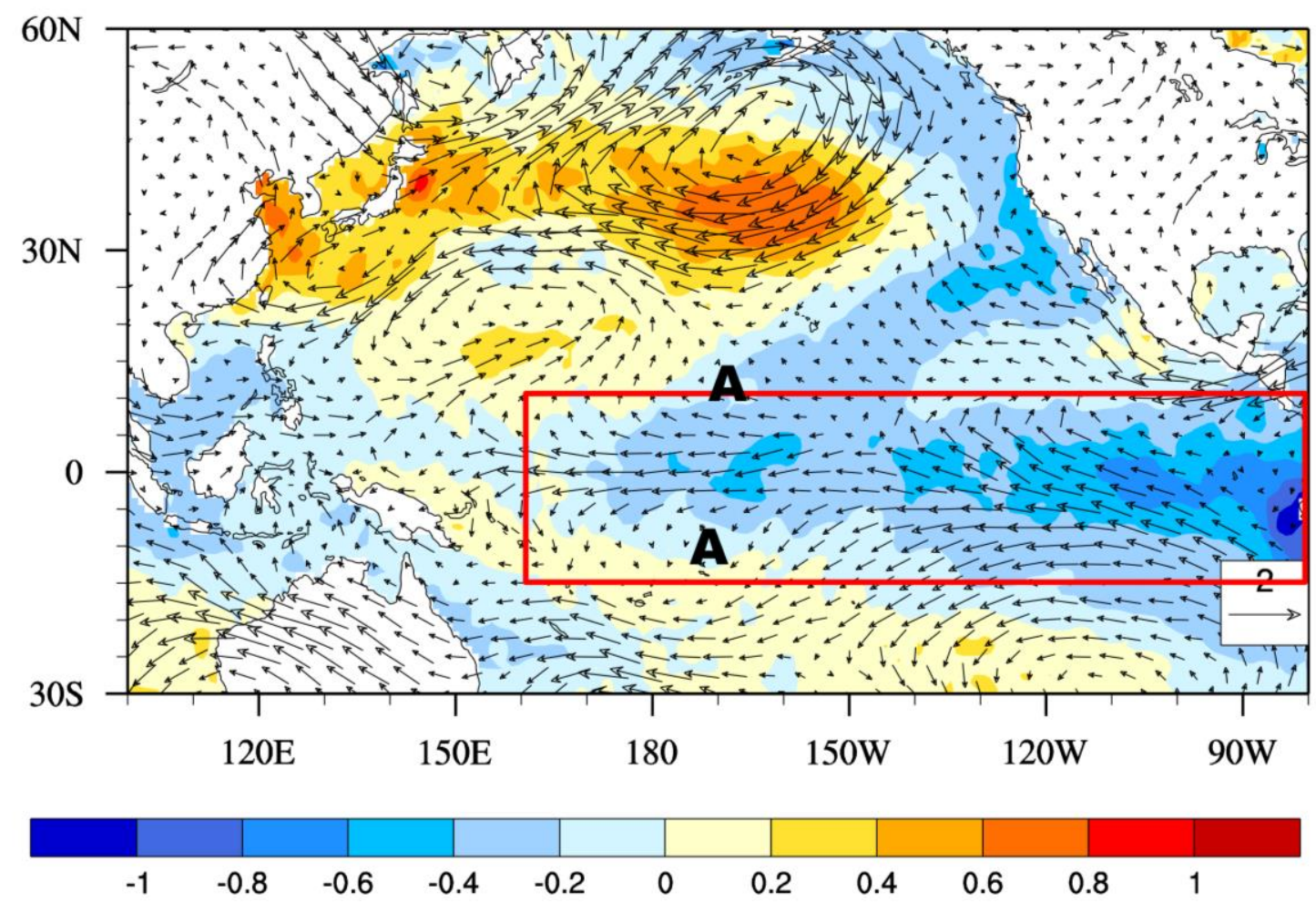

Fig. 9 Composite of interannual wind perturbation at $850 \mathrm{hPa}$ (vectors, $\mathrm{m} \mathrm{s}^{-1}$ ) and sea 478 surface temperature (SST) anomaly (shaded, K) in June. Markers "A" denote 479 anticyclonic gyres. The rectangle marks the equatorial eastern Pacific region $\left(15^{\circ} \mathrm{S}-\right.$ $\left.48010^{\circ} \mathrm{N}, 160^{\circ} \mathrm{E}-80^{\circ} \mathrm{W}\right)$, where cold SST anomaly $(-1 \mathrm{~K})$ is prescribed in the sensitivity 481 experiment. 


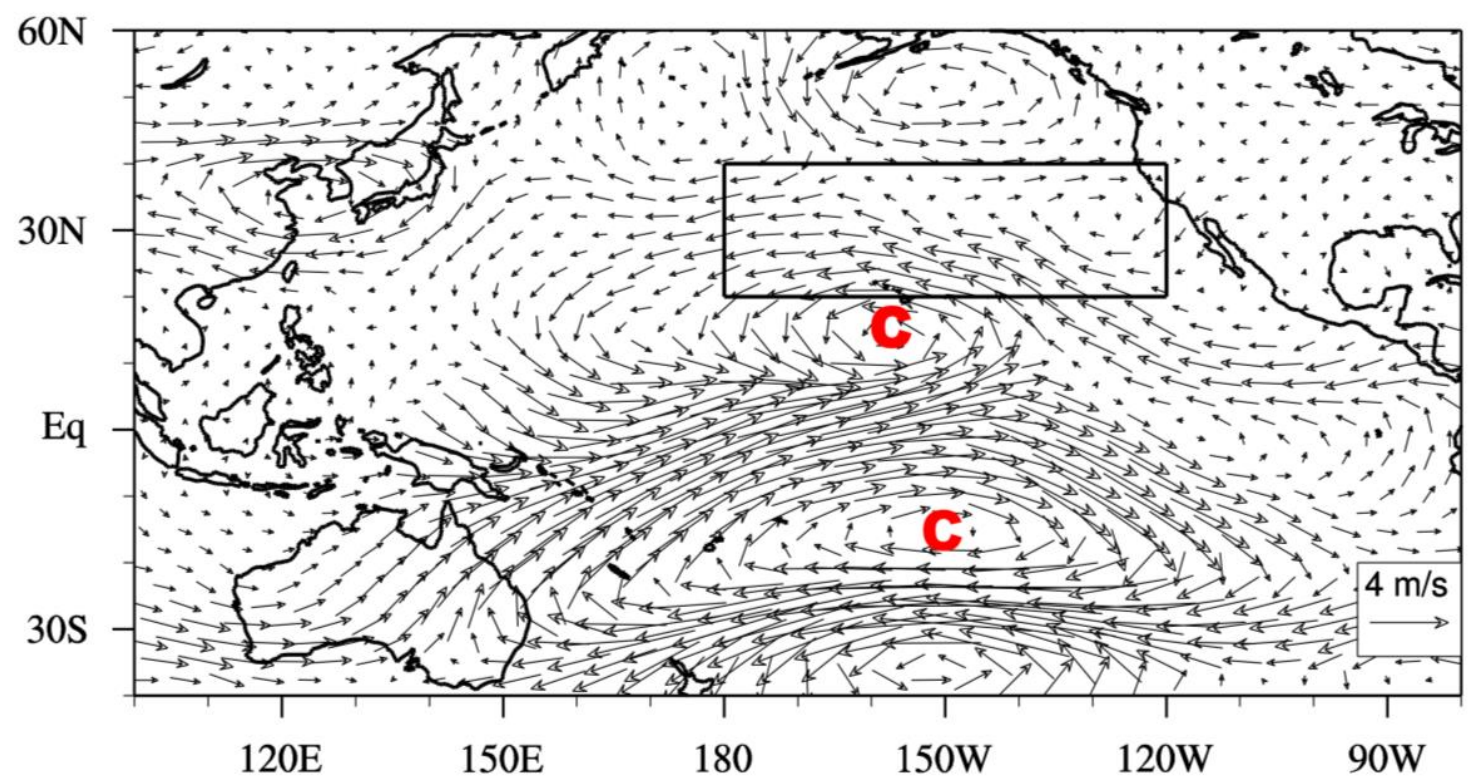

487 equatorial eastern Pacific region. Markers "C" denote cyclonic gyres. The rectangle 488 marks the Northern Pacific region $\left(20^{\circ} \mathrm{N}-40^{\circ} \mathrm{N}, 180^{\circ}-120^{\circ} \mathrm{W}\right)$. 